\title{
Triple Reuptake Inhibitors: A Premise and Promise
}

\author{
David M. Marks, MD ${ }^{1}$ \\ Chi-Un Pae, MD, PhD ${ }^{1,2}$ \\ Ashwin A. Patkar, MD ${ }^{1}$ \\ 1Department of Psychiatry, \\ Duke University Medical Center, \\ Durham, North Carolina, USA \\ 2Department of Psychiatry, \\ The Catholic University of Korea \\ College of Medicine, \\ Seoul, Korea
}

On the horizon there is a new class of psychoactive medications which work by inhibiting the neuronal reuptake of serotonin, norepinephrine, and dopamine. There are multiple potential indications for these drugs. Research suggests that they may have a role in treating depressive disorders, and it is plausible they may have potential efficacy in obesity, addiction, and pain syndromes. The current review describes some of the molecules in development presently and explores the research relevant to possible clinical uses for this class of medications.

KEY WORDS: Triple reuptake inhibitor, Serotonin, Norephinephrine, Dopamine.

$$
\text { Psychiatry Invest 2008;5:142-147 }
$$

\section{Introduction}

Prior to the 1980's, drug candidates were identified by testing laboratory-derived compounds in animal models and observing the effects. As biochemical and genetic research identified the molecular mechanisms that underlie disease, drug development began to focus on increasing selectivity with the goal of affecting only the target molecule identified as relevant in order to minimize side effects. ${ }^{1}$

In the past twenty five years, antidepressant drug development followed this trend, leading to molecules that specifically inhibit serotonin reuptake (SSRIs) or both serotonin and norepinephrine reuptake (SNRIs). These agents have more benign side effect profiles than tricyclic antidepressants (TCAs) or monoamine oxidase inhibitors (MAOIs) owing to a lack of histamine, acetylcholine, and alpha-adrenergic receptor antagonism. In short, the selectivity of these newer antidepressants effectively reduced adverse effects. Although better tolerability was a step forward in the treatment of depression and other disorders treated with antidepressants, the need remained for agents with improved efficacy and quicker onset of action. SSRIs and SNRIs have not shown advantages in efficacy or in onset of antidepressant response compared to TCAs or MAOIs. ${ }^{2,3}$ To date, only $65 \%$ of patients treated with antidepressants experience therapeutic response, ${ }^{2-5}$ and typical onset of action of antidepressants is approximately $2-4$ weeks.$^{6,7}$

Lately there has been a reversal of the trend towards selectivity in drug development across many therapeutic areas. Clinical studies of complex disorders as diverse as cancer and schizophrenia reveal that "dirty" drugs affecting a variety of targets tend to have better efficacy. ${ }^{1}$

Current antidepressant development efforts include the evaluation of triple reuptake inhibitors which block the reuptake of serotonin, norepinephrine, and dopamine from the synapse. It is theorized that the additive effect of enhancing neurotransmission in all three monoamine systems (broad spectrum) may lead to improved efficacy and quicker onset of antidepressant response. This review discusses the theory behind this development strategy as well as the preclinical and clinical data supporting the potential usefulness of triple reuptake inhibitors for depression and other disorders. 


\section{The Triple-Reuptake Premise}

Copious evidence links depression to deficiencies in neurotransmission of the monoamines serotonin, norepinephrine, and dopamine. ${ }^{8-12}$ TCAs and MAOIs were serendipitously discovered to be efficacious in depressed patients and subsequently became widely used for depression. Research since has demonstrated that these medications work by inhibiting the norepinephrine and serotonin transporters (e.g. TCAs $)^{13}$ and by inhibiting the intracellular catabolism of norepinephrine and serotonin (e.g. MAOIs). Simultaneously, depletion studies linked depression to deficient amounts of norepinephrine and serotonin ${ }^{14-16} \mathrm{Ra}$ tional drug design later led to SSRIs and SNRIs which have successfully led to reduced side effect burden as a result of their selectivity for monoamine reuptake sites. Other antidepressants have been developed which enhance norepinephrine and serotonin neurotransmission via other mechanisms; such medications include mirtazepine (presynaptic alpha-2 adrenergic antagonist), as well as trazodone and nefazodone (primarily presynaptic and postsynaptic 5-HT2 antagonists). Less attention has been given to affecting dopamine transmission in depression, although data indicate the important role of mesolimbic dopamine in moderating motivation and reward-related behavior which are typically disrupted in depression. ${ }^{17,18}$ Furthermore, antidepressants have been shown to sensitize mesolimbic dopamine receptors in animal and human studies, findings which have led to the hypothesis that enhancing synaptic dopamine availability may lead to more rapid antidepressant response. ${ }^{17}$ The dopamine and norepinephrine reuptake inhibitor bupropion was developed in the 1980's as an antidepressant, ${ }^{19}$ and it has since been repeatedly shown to boost the therapeutic response to norepinephrinergic and/or serotonergic antidepressants (and decrease sexual side effects) when used as augmentation. ${ }^{20-22}$

Additional data indicate that the stimulant class of medications, which induce release and block reuptake of dopamine and norepinephrine, augment and hasten antidepressant response when combined with $\mathrm{TCA}^{23-25} \mathrm{MAOIs},{ }^{26,27}$ and SSRIs/SRNIs ${ }^{28,29}$ Finally, dopamine agonists themselves (bromocriptine, pergolide) have shown efficacy as augmenting agents with antidepressants in open label studies. ${ }^{30,31}$

Thus, it seems that serotonin, norepinephrine, and dopamine systems are all related to the pathophysiology of depression and as such are relevant targets for pharmacological intervention. This premise has ushered the development of medications which enhance neurotransmission of all three systems in an effort to provide more reliable efficacy and quicker therapeutic effect.

\section{The Debate: Is Broader Better?}

In a reversal of the move towards selectivity that led to the SSRIs in the 1980's and 1990's, the SNRIs were developed under the premise that a broader spectrum of neurotransmitter reuptake inhibition would lead to greater antidepressant efficacy and/or more rapid onset of action. Data accumulated to date is mixed regarding the usefulness of this strategy. With regard to rapidity of onset, venlafaxine performed well in a placebo-controlled trial in hospitalized depressed patients, demonstrating efficacy benefit within one week of treatment initiation. ${ }^{32}$ Similarly, venlafaxine produced earlier time to remission of depression compared to SSRIs in an open-label trial. ${ }^{33} \mathrm{~A}$ meta-analysis of eight studies comparing venlafaxine to SSRIs and placebo demonstrates earlier time to remission in venlafaxine-treated patients consistently across age and gender groups. ${ }^{34}$ The authors also cite remission rates of $45 \%, 35 \%$, and $25 \%$ in patients treated with venlafaxine, SSRIs, and placebo respectively, yielding an odds ratio for remission of 1.5 favoring venlafaxine over SSRIs. ${ }^{35}$ Two more recent large meta-analyses of studies comparing SNRIs to SSRIs revealed a smaller efficacy advantage in favor of SNRIs $\left(4.3-5.9 \%\right.$ higher remission rate)..$^{36,37}$ In these later meta-analyses, the number needed to treat (NNT) statistic shows that 17-24 patients would need to be treated with SNRIs to yield one additional responder, ${ }^{36,37}$ confronting the notion that SNRIs offer a clinically relevant advantage over SSRIs with respect to likelihood of achieving remission of depression.

Other data endorses the thrust towards increased neurotransmitter selectivity. In particular, a meta-analysis of the highly selective SSRI escitalopram (S-isomer of citalopram) suggests that this medication is superior in efficacy to other SSRIs and to the SNRI venlafaxine (grouped together) on the outcomes of response rate, remission rate, and overall treatment outcome. ${ }^{38}$ A second meta-analysis indicates more rapid onset of action of escitalopram compared to other SSRIs and venlafaxine extended-release (grouped together).$^{39}$ Thus, it remains controversial whether certain antidepressants confer clinically relevant advantages in rapidity of onset or overall efficacy for depression, and whether such differences are related to the breadth of their neurotransmitter reuptake inhibition.

It should also be noted that currently available dual reuptake inhibitors differ in their relative potencies at monoamine transporters. Milnacipran blocks serotonin and norepinephrine reuptake equally, whereas greater selectivity at serotonin reuptake sites is characteristic of venlafaxine (30-fold) and duloxetine (10-fold). ${ }^{40}$ Clinical ramifications of these differences in selectivity are poorly understood. 


\section{Compounds in Development}

Despite the structural similarity of the norepinephrine, serotonin, and dopamine transporters, synthesis of bioavailable and safe molecules which appreciably inhibit all three transporters has been challenging. ${ }^{41}$ Additionally, the optimal selectivity at the three transporter sites is unknown, and it is plausible that different potency ratios mean different clinical effects. Two families of compounds in development are analogs of the dual reuptake inhibitors milnacipran and venlafaxine. Several milnacipran derivatives have been developed in search of molecules with more potent N-methyl-D-aspartic acid (NMDA) antagonism. ${ }^{42,43}$ More recently, analogs have been synthesized to evaluate their relative monoamine transporter inhibition potency and selectivity. An isomer of one such analog (-) -8h functions as a triple reuptake inhibitor in vitro. ${ }^{40}$ To date, animal or human antidepressant studies have not been published with this compound.

Racemic analogs of venlafaxine referred to as PRC025 and PRC050 are highly potent at human norepinephrine (NE), serotonin (SER), and dopamine (DA) transporters and inhibit the reuptake of these monoamines into rat brain synaptosomes. ${ }^{4}$ These compounds exhibited antidepressant-like characteristics equal to imipramine in well-accepted rat models of antidepressant effect; both PRC025 and PRC050 increased time spent swimming and reduced time spent immobile in the forced swim test and reduced time spent immobile in the tail suspension test. ${ }^{4}$

DOV Pharmaceuticals has developed triple reuptake inhibitors from a class of azabicyclohexanes chemically related to bicifadine. Three of these compounds (DOV 216,303, DOV 21,947, and DOV 102,677) have been shown to block transport of human recombinant NE, SER, and DA transporters with clinically-relevant potency (Table 1) ${ }^{8,17,44,45}$ Also, all three of these compounds demonstrated antidepressant properties in rodent models; 21,947 reduced immobility during forced swim test and tail suspension test $,{ }^{44} 102,677$ reduced immobility during forced swim test, ${ }^{8}$ and 216,303 reduced immobility during forced swim test and reversed tetrabenazine-induced ptosis. ${ }^{17}$ Human studies with DOV 216,303 show that it is well-tolerated at clinically appropriate doses with minor gastrointestinal side effects ranging from $19-57 \% .^{17,45}$ A small citalopram-controlled clinical trial of DOV 216,303 ( $n=67)$ yielded significant improvements in Hamilton Depression Rating Scale (HAM-D) scores in both groups at both the one-week and two-week time points, although the study lacked a placebo group. ${ }^{17} \mathrm{Bi}-$ cifadine (1-p-tolyl-3-azabicyclo [3.1.0] hexane) itself has been pharmacologically characterized, and it has been shown to inhibit monoamine neurotransmitter uptake by recombinant human transporters in vitro with a relative potency of norepinephrine : serotonin : dopamine of 1 : $2: 17 .^{46}$ To date, published preclinical research has focused on the potential antinociceptive properties of bicifadine,${ }^{46}$ although its utility as an antidepressant warrants exploration.

The novel triple reuptake inhibitor tesofensine (NS 2330) has not been systematically studied regarding its clinical or preclinical antidepressant effects. Similar to antidepressants, ${ }^{47}$ this agent has demonstrated neuroprotective effects including increasing brain derived neurotrophic factor (BDNF) and neuronal proliferation in the rat hippocampus. ${ }^{48}$

Presumably other triple reuptake inhibitors are in various developmental phases, and the current discussion of compounds in development should not be considered exhaustive. A summary of described compounds appears below in Table 1 .

\section{Other Potential Indications for Triple Reuptake Inhibitors}

Like other classes of antidepressant medications, triple reuptake inhibitors likely hold promise for a variety of therapeutic indications. One emerging area of research concerns the potential antinociceptive effects of triple inhibitors, which is expected given the copious data supporting the utility of TCAs and SNRIs for pain syndromes. Preclinical research with bicifadine demonstrates its antinociceptive effects in animal models of acute, persistent, and chronic pain including inflammatory, visceral, and nociceptive paradigms. These effects were reduced in some experimental conditions by the coadminstration of sulpride (a dopamine-2 receptor antagonist), suggesting that enhancement of dopamine neurotransmission is important for the full antinociceptive effect of bicifadine. ${ }^{46}$

One published preclinical study describes the effect of the "balanced" triple reuptake inhibitor DOV 102,677 in reducing volitional alcohol consumption in ethanolpreferring rats without decreasing food or water consumption. ${ }^{49}$ It should be noted that monoamine reuptake inhibitors have historically performed better in animal models of addiction than in human clinical trials. However, it is possible that agents which inhibit dopamine reuptake may offer improved efficacy in addictive disorders due to the link between dopamine and reward-motivated behaviors. Subsequent clinical trials in subjects with addictive disorders will elucidate the potential for triple reuptake inhibitors to reduce addictive behaviors.

The prodopaminergic potential of tesofensine led to a proof-of-concept study of this agent in the treatment of Parkinson's disease (PD). In this adequately-powered 
DM Marks et al.

TABLE 1. Characteristics and pharmacokinetic parameters of triple reuptake inhibitors in development

\begin{tabular}{|c|c|c|c|c|c|c|c|}
\hline Products & Compounds & Origin & $\begin{array}{l}\text { Evidence of } \\
\text { antidepressant } \\
\text { potential }\end{array}$ & $\begin{array}{l}\text { Affinity } \\
K_{i}(n m / L) \\
N E: S E R: D A a\end{array}$ & $\begin{array}{l}\text { Potency } \\
\text { IC } C_{50}(n M) \\
\text { NE : SER : DAa }\end{array}$ & $\begin{array}{l}\text { Half- } \\
\text { life } \\
(\mathrm{hr})\end{array}$ & $\begin{array}{l}\text { Tmax } \\
\text { (Time to peak } \\
\text { concentration } \\
\text { in hrs) }\end{array}$ \\
\hline$(-)-8 \mathrm{~h}$ & $\begin{array}{l}(-)-(1 R, 2 S) \text {-naphthyl } \\
\text { derivative of milnacipran }\end{array}$ & & None & & $5: 18: 140$ & & \\
\hline PRC025 & $\begin{array}{l}\text { (2SR,3RS) -N,N-dimethyl-3- } \\
\text { cyclohexyl-3-hydroxy-2- } \\
\text { (2'-naphthyl) propylamine }\end{array}$ & $\begin{array}{l}\text { Racemic } \\
\text { analogue of } \\
\text { venlafaxine }\end{array}$ & $\begin{array}{l}\text { Animal/ } \\
\text { Preclinical }\end{array}$ & $10: 6: 53$ & & & \\
\hline PRC050 & $\begin{array}{l}\text { (2RS,3RS) -N-methyl-3- } \\
\text { hydroxy-2-(2'-naphthyl) -3- } \\
\text { phenylpropylamine }\end{array}$ & $\begin{array}{l}\text { Racemic } \\
\text { analogue of } \\
\text { venlafaxine }\end{array}$ & $\begin{array}{l}\text { Animal/ } \\
\text { Preclinical }\end{array}$ & $1.2: 12: 43$ & & & \\
\hline DOV 216,303 & $\begin{array}{l}{[( \pm) \text {-1-(3,4-dichlorophenyl)- }} \\
\text { 3-azabicyclo-[3.1.0] } \\
\text { hexane } \\
\text { hydrochloride] }\end{array}$ & & $\begin{array}{l}\text { Animal/ } \\
\text { Preclinical } \\
\text { Small human } \\
\text { clinical trial } \\
\text { (not placebo- } \\
\text { controlled) }\end{array}$ & & $21: 14: 78$ & $\begin{array}{l}\text { Approx. } \\
3.3 \text { to } \\
4.4\end{array}$ & Approx. 1 \\
\hline DOV 21,947 & $\begin{array}{l}{[(+) \text {-1-(3,4-dichlorophenyl)- }} \\
\text { 3-azabicyclo-[3.1.0] } \\
\text { hexane hydrochloride] }\end{array}$ & $\begin{array}{l}\text { (+)-enantiomer } \\
\text { of } \\
\text { DOV } 216,303\end{array}$ & $\begin{array}{l}\text { Animal/ } \\
\text { Preclinical }\end{array}$ & $262: 99: 213$ & $23: 12: 96$ & & \\
\hline DOV 102,677 & $\begin{array}{l}\text { [(-)-1-(3,4-dichlorophenyl)- } \\
\text { 3-azabicyclo-[3.1.0] } \\
\text { hexane } \\
\text { hydrochloride]) }\end{array}$ & $\begin{array}{l}(-) \text {-enantiomer } \\
\text { of } \\
\text { DOV } 216,303\end{array}$ & $\begin{array}{l}\text { Animal/ } \\
\text { Preclinical }\end{array}$ & $1030: 740: 222$ & $103: 133: 129$ & & \\
\hline Bicifadine & $\begin{array}{l}(+/-) \text {-1-(4-methylphenyl)- } \\
\text { 3-azabicyclo-[3.1.0] } \\
\text { hexane HCl) ] }\end{array}$ & DOV 220,075 & None & $\begin{array}{l}5.0: 2.4: 5.2 \\
(\mu \mathrm{M})\end{array}$ & $55: 117: 910$ & $\begin{array}{l}\text { Approx. } \\
3.5\end{array}$ & Approx. 1 \\
\hline $\begin{array}{l}\text { Tesofensine } \\
\text { (NS2330) }\end{array}$ & $\begin{array}{l}\text { 8-azabicyclo [3.2.1] octane, } \\
\text { 3-(3,4-dichlorophenyl)- } \\
\text { 2-(ethoxymethyl)-8- } \\
\text { methyl-, [1R-(2-endo, } \\
\text { 3-exo) ]-,2-hydroxy-1,2,3- } \\
\text { propanetricarboxylate }\end{array}$ & & None & & $1.7: 11: 65$ & $\begin{array}{l}\text { Approx. } \\
230\end{array}$ & Approx. 6-8 \\
\hline
\end{tabular}

study $(n=261)$ with multiple dosage arms corresponding to up to $77 \%$ dopamine transporter occupancy, tesofensine did not outperform placebo. ${ }^{50}$ Two smaller openlabel studies of tesofensine and the related compound brasofensine also failed to demonstrate benefit in PD. ${ }^{51,52}$ One possible explanation is homeostatic reduction in dopamine synthesis and release. ${ }^{50}$ In contrast, in a phase IIa pilot study in Alzheimer's disease, tesofensine treatment was associated with cognitive improvements $;{ }^{51}$ the physiological mechanism of this observation is unclear, although it has been proposed that tesofensine indirectly stimulates cholinergic neurotransmission. ${ }^{51}$

Weight loss has been observed as an adverse event in studies of tesofensine, ${ }^{50}$ prompting further research for the indication of obesity. The pharmaceutical company Neurosearch has conducted a phase IIb proof-of-concept dose-finding study and a subsequent study of metabolic outcomes using tesofensine; both of these studies indicate that tesofensine is efficacious in promoting weight loss in obese subjects. ${ }^{53}$ The triple reuptake inhibitor si- butramine is approved by the United States Food and Drug Administration (FDA) for the indication of obesity. Research is generally lacking regarding the antidepressant potential of sibutramine, although a small study in obese and overweight subjects $(n=60)$ suggests that it has mood-enhancing effects. ${ }^{54}$

\section{Discussion}

The impetus to develop triple reuptake inhibitors is a natural consequence of the rich drug development history occurring over the past fifty years. We have come a long way since the serendipitous discovery that TCAs and MAOIs exert antidepressant effects. Rational drug design has allowed us to customize the receptor profiles of potential antidepressant drugs and to target specific monoamine reuptake transporters. Current strategies involve developing multiple analogues of dual reuptake inhibitors and characterizing their receptor profiles in order to develop a quiver of molecules with clinically-re- 
levant activity at all three monoamine reuptake sites. The ideal ratio of transporter site potencies that a triple reuptake inhibitor should exhibit remains unknown, and hopefully the diversity of molecules in development will shed light on this issue. Future research will undoubtedly involve clinical study of various triple reuptake inhibitors to determine whether any of them offer advantages over currently approved antidepressants in efficacy, rapidity of onset, or side effect profile. Research published to date tends to support that antidepressants vary modestly in various outcomes related to efficacy. Yet, findings are mixed regarding whether broader spectrum agents or highly serotonin-selective agents confer the best efficacy for depression, although the argument in favor of broader spectrum agents is more believable. Stronger evidence for superiority of broad spectrum agents appears in research on various pain syndromes such as fibromyalgia and headache; TCAs and SNRIs have shown more consistent benefit than SSRIs, ${ }^{55,56}$ possibly related to serotonin's propensity to both facilitate and inhibit pain in contrast to norepinephrine which is purely antinociceptive. The role of dopamine in pain processing is less established, although preclinical evidence suggests that dopaminergic neurotransmission in the nucleus accumbens at least partially mediates the antinociceptive property of nitrous oxide. ${ }^{57}$ Thus, triple reuptake inhibitors may have a clinical role in the treatment of pain syndromes as demonstrated by bicifadine data. ${ }^{47}$

Of note, concern has been expressed that triple reuptake inhibitors may produce broader side effect burden without enhancing efficacy over more selective agents. ${ }^{58}$ In actuality, it is plausible that triple reuptake inhibitors that minimize blockade at histaminergic, cholinergic, and alpha-adrenergic receptors may yield the most favorable tolerability of all antidepressants with less sexual side effects than SSRIs or SNRIs. By way of example, bupropion has long been used to treat antidepressant-related sexual dysfunction, presumably through its dopaminergic effects. ${ }^{19}$ Many of these questions will be answered by subsequent research.

\section{REFERENCES}

1. Frantz S. Drug discovery: playing dirty. Nature 2005;437:942-943.

2. Steffens DC, Krishnan KR, Helms MJ. Are SSRIs better than TCAs? Comparison of SSRIs and TCAs: a meta-analysis. Depress Anxiety 1997;6:10-18.

3. Shelton RC. The dual-action hypothesis: does pharmacology matter? J Clin Psychiatry 2004;65 suppl 17:5-10.

4. Shaw AM, Boules M, Zhang Y, Williams K, Robinson J, Carlier PR, et al. Antidepressant-like effects of novel triple reuptake inhibitors, PRC025 and PRC050. Eur J Pharmacol 2007;555:30-36.

5. Richelson E. Pharmacology of antidepressants. Mayo Clin Proc 2001; 76:511-527.

6. Stassen HH, Angst J, Hell D, Scharfetter C, Szegedi A. Is there a com- mon resilience mechanism underlying antidepressant drug response? Evidence from 2848 patients. J Clin Psychiatry 2007;68:1195-1205.

7. Paul IA. Excitatory amino acid signaling, major depression, and the action of antidepressants. Pharm News 2001;8:33-44.

8. Popik P, Krawczyk M, Golembiowska K, Nowak G, Janowsky A, Skolnick P, et al. Pharmacological profile of the "triple" monoamine neurotransmitter uptake inhibitor, DOV 102,677. Cell Mol Neurobiol 2006;26:857-873.

9. Randrup A, Munkvad J, Fog R, Gerlach J, Molander L, Kjellberg B, et al. Mania, depression and brain dopamine. In: Essman WB, Valzelli L, editors. Current Developments in Psychopharmacology, vol 2. New York: Spectrum Publications, 1975, p.206-248.

10. D'Aquilla PS, Collu M, Gessa GL, Serra G. The role of dopamine in the mechanism of action of antidepressant drugs. Eur J Pharmacol 2000;405:365-373.

11. Willner P. Dopaminergic mechanisms in depression and mania. In: Watson S, editor. Psychopharmacology: The Fourth Generation of Progress. New York: Lippincott Williams \& Wilkins;2000.

12. Skolnick P. Dopamine and depression. In: Schmidt W, editor. Dopamine and Glutamate in Psychiatric Disorders. Totowa: Humana Press, 2005, p.199-214.

13. Axelrod J, Whitby LG, Hertting G. Effects of psychotropic drugs on the uptake of H3-norepinephrine by tissues. Science 1961;133:383-384.

14. Young SN, Smith SE, Pihl RO, Ervin FR. Tryptophan depletion causes a rapid lowering of mood in normal males. Psychopharmacology (Berl) 1985;87: 173-177.

15. Delgado PL, Miller HL, Salomon RM, Licinio J, Heninger GR, Gelenberg AJ, et al. Monoamines and the mechanism of antidepressant action: effects of catecholamine depletion on mood of patients treated with antidepressants. Psychpharmacol Bull 1993;29:389-396.

16. Delgado PL. How antidepressants help depression: mechanisms of action and clinical response. J Clin Psychiatry 2004;65 Suppl 4:25-30.

17. Skolnick P, Krieter P, Tizzano J, Basile A, Popik P, Czobor P, et al. Preclinical and clinical pharmacology of DOV 216,303, a "triple" reuptake inhibitor. CNS Drug Rev 2006;12:123-134.

18. Naranjo CA, Tremblay LK, Busto UE. The role of the brain reward system in depression. Prog Neuropsychopharmacol Biol Psychiatry 2001; 25:781-823.

19. Wilkes S. Bupropion. Drugs Today (Barc) 2006;42:671-681.

20. Zisook S, Rush AJ, Haight BR, Clines DC, Rockett CB. Use of bupropion in combination with serotonin reuptake inhibitors. Biol Psychiatry 2006;59:203-210.

21. Fava M. Augmentation and combination strategies in treatment-resistant depression. J Clin Psychiatry 2001;62 Suppl 18:4-11.

22. Bodkin JA, Lasser RA, Wines JD Jr, Gardner DM, Baldessarini RJ. Combining serotonin reuptake inhibitors and bupropion in partial responders to antidepressant monotherapy. J Clin Psychiatry 1997;58: 137-145.

23. Gwirtsman HE, Szuba MP, Toren L, Feist M. The antidepressant response to tricyclics in major depressives is accelerated with adjuctive use of methylphenidate. Psychopharmacol Bull 1994;30:157-164.

24. Wharton RN, Perel JM, Dayton PG, Malitz S. A potential clinical use for methylphenidate with tricyclic antidepressants. Am J Psychiatry 1971;127:1619-1625.

25. Drimmer EJ, Gitlin MJ, Gwirtsman HE. Desipramine and methylphenidate combination treatment for depression: case report. Am J Psychiatry 1983;14:241-242.

26. Feigner JP, Herbstein J, Damlouji N. Combined MAOI, TCA, and direct stimulant therapy of treatment-resistant depression. J Clin Psychiatry 1985;46:206-209.

27. Fawcett J, Kravitz HM, Zejecka JM, Schaff MR. CNS stimulant potentiation of monoamine oxidase inhibitors in treatment-refractory depression. J Clin Psychopharmacol 1991;11:127-132.

28. Stoll AL, Pillay SS, Diamond L, Workum SB, Cole JO. Mehyphenidate augmentation of selective serotonin reuptake inhibitors: a case 
series. J Clin Psychiatry 1996;57:72-76.

29. Masand PS, Anand VS, Tanquary JF. Psychostimulant augmentation of second generation antidepressants: a case series. Depress Anxiety 1998;7:89-91.

30. Inoue T, Tsuchiya K, Miura J, Sakakibara S, Denda K, Kasahara T, et al. Bromocriptine treatment of tricyclic and heterocyclic antidepressant-resistant depression. Biol Psychiatry 1996;40:151-153.

31. Izumi $\mathrm{T}$, Inoue $\mathrm{T}$, Kitagawa $\mathrm{N}$, Nishi $\mathrm{N}$, Shimanaka $\mathrm{S}$, Takahashi $\mathrm{Y}$, et al. Open pergolide treatment of tricyclic and heterocyclic antidepressant-resistant depression. J Affect Disord 2000;61:127-132.

32. Guelfi JD, White C, Hackett D, Guichoux JY, Magni G. Effectiveness of venlafaxine in patients hospitalized for major depression and melancholia. J Clin Psychiatry 1995;56:450-458.

33. Shelton CI. Long-term management of major depressive disorder: are differences among antidepressant treatments meaningful? J Clin Psychiatry 2004;65 Suppl 17:29-33.

34. Entsuah AR, Huang H, Thase ME. Response and remission rates in different subpopulations with major depressive disorder administered venlafaxine, selective serotonin reuptake inhibitors, or placebo. J Clin Psychiatry 2001;62:869-877.

35. Thase ME, Entsuah AR, Rudolph RL. Remission rates during treatment with venlafaxine or selective serotonin reuptake inhibitors. Br J Psychiatry 2001;178:234-241.

36. Papkostas GI, Thase ME, Fava M, Nelson JC, Shelton RC. Are antidepressant drugs that combine serotonergic and noradrenergic mechanisms more effective than the selective serotonin reuptake inhibitors in treating major depressive disorder? A meta-analysis of studies of newer agents. Biol Psychiatry 2007;62:1217-1227.

37. Nemroff CB, Entsuah R, Benattia I, Demitrack M, Sloan DM, Thase ME. Comprehensive analysis of remission (COMPARE) with venlafaxine versus SSRIs. Biol Psychiatry 2008;63:424-434.

38. Kennedy SH, Andersen HF, Lam RW. Efficacy of escitalopram in the treatment of major depressive disorder compared with conventional selective serotonin reuptake inhibitors and venlafaxine XR: a metaanalyis. J Psychiatry Neurosci 2006;31:122-131

39. Kasper S, Spadone C, Verpillat P, Angst J. Onset of action of escitalopram compared with other antidepressants: results of a pooled analysis. Int Clin Psychopharmacol 2006;21:105-110.

40. Roggen H, Kehler J, Stensbol TB, Hansen T. Synthesis of enantiomerically pure milnacepran analogs and inhibition of dopamine, serotonin, and norepinephrine transporters. Bioorg Med Chem Lett 2007; 17:2834-2837.

41. Skolnick P, Popik P, Janowsky A, Beer B, Lippa AS. "Broad spectrum" antidepressants: is more better for the treatment of depression? Life Sci 2003;73:3175-3179.

42. Shuto S, Ono S, Imoto H, Yoshii K, Matsuda A. Synthesis and biological activity of conformationally restricted analogues of milnacipran: (1S, 2R) -1-phenyl-2-[(R) -1-amino-2-propynyl] -N,N- diethylcyclopropanecarboxamide is a novel class of NMDA receptor channel blocker. J Med Chem 1998;41:3507-3514.

43. Kazuta Y, Tsujita R, Ogawa K, Hokonohara T, Yamashita K, Morino $\mathrm{K}$, et al. Synthesis of (1S,2R) -1-phenyl-2-[(S) -1-aminopropyl] -N,N- diethylcyclopropanecarboxamide (PPDC) derivatives modified at the carbamoyl moiety as a new class of NMDA receptor antagonists. Bioorg Med Chem 2002;10:1777-1791.

44. Skolnick P, Popik P, Janowsky A, Beer B, Lippa AS. Antidepressantlike actions of DOV 21,947: a "triple" reuptake inhibitor. Eur J Pharmacol 2003;461:99-104.

45. Beer B, Stark J, Krieter P, Czobar P, Beer G, Lippa A, et al. DOV 216,303, a "triple" reuptake inhibitor: safety, tolerability, and pharmacokinetic profile. J Clin Pharmacol 2004;44:1360-1367.

46. Basile AS, Janowsky A, Golembiowska K, Kowalska M, Tam E, Benveniste $\mathrm{M}$, et al. Characterization of the antinociceptive actions of bicifadine in models of acute, persistent, and chronic pain. J Pharmacol Exp Ther 2007;321:1208-1225.

47. Czéh B, Michaelis T, Watanabe T, Frahm J, de Biurrun G, van Kampen $\mathrm{M}$, et al. Stress-induced changes in cerebral metabolites, hippocampal volume, and cell proliferation are prevented by antidepressant treatment with tianeptine. Proc Nat Acad Sci U S A 2001;98:1279612801.

48. Larsen MH, Rosenbrock H, Sams-Dodd F, Mikkelsen JD. Expression of brain derived neurotrophic factor, activity-regulated cytoskeleton protein mRNA, and enhancement of adult hippocampal neurogenesis in rats after sub-chronic and chronic treatment with the triple monoamine re-uptake inhibitor tesofensine. Eur J Pharmacol 2007;555:115-121.

49. McMillen BA, Shank JE, Jordan KB, Williams HL, Basile AS. Effect of DOV 102,677 on the volitional consumption of ethanol by Myers' high ethanol-preferring rat. Alcohol Clin Exp Res 2007;31:1866-1871.

50. Hauser RA, Salin L, Juhel N, Konyago VL. Randomized trial of the triple monoamine reuptake inhibitor NS2330 (tesofensine) in early Parkinson's disease. Mov Disord 2007;22:359-365.

51. Thatte U. NS-2330 (Neurosearch) . Curr Opin Investig Drugs 2001;2: 1592-1594.

52. Frackiewicz EJ, Jhee SS, Shiovitz TM, Webster J, Topham C, Dockens RC, et al. Brasofensine treatment for Parkinson's disease in combination with levodopa/carbidopa. Ann Pharmacother 2002;36: 225-230.

53. Available at Tesofensine. www.neurosearch.com. Accessed February $15,2008$.

54. Kiortsis DN, Tsouli S, Fillipatos TD, Konitsiotis S, Elisaf MS. Effects of sibutramine and orlistat on mood in obese and overweight subjects: a randomized study. Nutr Metab Cardiovasc Dis 2008;18:207-210.

55. O'Malley PG, Jackson JL, Santoro J, Tomkins G, Balden E, Kroenke $\mathrm{K}$. Antidepressant therapy for unexplained symptoms and symptoms syndromes. J Fam Pract 1999;48:980-990.

56. Arnold LM. Duloxetine and other antidepressants in the treatment of patients with fibromyalgia. Pain Med 2007;8 Suppl 2:S63-S74

57. Koyanagi S, Himukashi S, Mukaida K, ShichinoT, Fukuda K. Dopamine D2-like receptor in the nucleus accumbens is involved in the antinociceptive effect of nitrous oxide. Anesth Analg 2008;106:19041909.

58. Owens MJ. Selectivity of antidepressants: from the monoamine hypothesis of depression to the SSRI revolution and beyond. J Clin Psychiatry 2004;65 Suppl 4:5-10. 